\title{
The Efficacy and Safety of Lubiprostone for Constipation in Cancer Patients Compared with Non-cancer Patients: A Retrospective Cohort Study
}

\author{
Hikaru Sada,${ }^{a}$ Makoto Kajizono, ${ }^{a}$ Souichiro Ushio, ${ }^{a}$ Satoru Esumi,${ }^{a}$ Yoshihisa Kitamura, ${ }^{* a, b}$ and \\ Toshiaki Sendo ${ }^{a}$ \\ ${ }^{a}$ Department of Pharmacy, Okayama University Hospital; 2-5-1 Shikata-cho, Kita-ku, Okayama 700-8558, \\ Japan: and ${ }^{b}$ Department of Pharmacotherapy, School of Pharmacy, Shujitsu University; 1-6-1 Nishigawara, Naka- \\ ku, Okayama 703-8516, Japan.
}

Received May 7, 2020; accepted July 30, 2020

Lubiprostone is an effective drug for various types of constipation in patients without cancer; however, there is no report on its efficacy and safety in patients with cancer. Our purpose was to evaluate the efficacy and safety of lubiprostone for constipation in cancer patients. We retrospectively studied 124 patients (cancer, $N=67$ ) who were treated with lubiprostone for constipation in our hospital between June 2013 and May 2016. The number of bowel movements (BMs) increased in the both the cancer and non-cancer groups. The mean change in BM frequency did not differ between the two groups. Approximately $70 \%$ of patients in both groups had an initial BM within $24 \mathrm{~h}$ after administration of lubiprostone. The most common lubiprostonerelated adverse events in both groups were diarrhea $(38.8 \mathrm{vs} .14 \%)$, and nausea $(22.4 \mathrm{vs} .8 .8 \%)$. No lubiprostone-related serious adverse events occurred. Discontinuation due to the side effects of lubiprostone was more frequent in cancer patients $(p=\mathbf{0 . 0 2 3})$. Logistic regression analysis showed that the risk of discontinuation of lubiprostone in cancer patients was high in patients with a body-mass index $(B M I)<22$, and low in patients using opioids and magnesium oxide dosage $\geq 1000 \mathrm{mg} / \mathrm{d}$. Our study showed that while lubiprostone was as effective in cancer patients as in non-cancer patients, in cancer patients it was associated with a high incidence of diarrhea and nausea side effects and warranted caution, especially in patients with a low BMI.

Key words lubiprostone; constipation; cancer; body-mass index; opioid; magnesium oxide

\section{INTRODUCTION}

Among patients with advanced cancer, persistent constipation is a common symptom. A systematic review by Solano, Gomes and Higginson determined that the prevalence of constipation in patients with any type of cancer was $23-65 \%,{ }^{1)}$ whereas the prevalence of chronic constipation in non-cancer patients is $2-27 \%{ }^{2,3)}$ The prevalence of constipation in patients with cancer receiving palliative care is higher $\left.(32-87 \%){ }^{4}\right)$ The prevalence of opioid-induced constipation (OIC) in Japanese patients with cancer is approximately $40 \%{ }^{5}{ }^{5}$ Opioids are a major responsible agent for constipation in cancer patients. The National Comprehensive Cancer Network $(\mathrm{NCCN})$ guidelines recommend preventative treatment of OIC in patients with cancer using irritant laxatives and/or stool softeners. ${ }^{6}$ In Japan, magnesium oxide (MgO) is routinely used as a stool softener, and administration of $1000 \mathrm{mg} / \mathrm{d}$ or more of $\mathrm{MgO}$ is reported to be effective in the prevention of OIC in patients with cancer. ${ }^{5}$ On the other hand, constipation due to causes other than opioids is often observed in cancer patients. ${ }^{7)}$ The prevalence of constipation in advanced cancer patients without opioids is $64 \%{ }^{8)}$ In about $50 \%$ of hospitalized cancer patients not receiving opioids, laxatives are routinely used.9) Although one systematic review reported little difference in efficacy and adverse events of various laxatives in patients with cancer, ${ }^{10}$ there is no evidence for the efficacy of laxatives against constipation caused by factors other than opioids in patients with cancer. Therefore, regardless of the use of opioids, adjustments must be made for each patient with cancer so that the response suits bowel movements (BMs) in clinical settings. ${ }^{4}$

Lubiprostone is an oral medication that selectively activates type- 2 chloride channels of the intestinal tract and increases secretion of intestinal juice without impacting serum electrolytes. ${ }^{11)}$ Previous studies have reported that lubiprostone increases the frequency of spontaneous bowel movements (SBMs) in patients with chronic idiopathic constipation (CIC), ${ }^{12,13)}$ irritable bowel syndrome with constipation (IBS-C) ${ }^{14,15)}$ and OIC in patients with chronic non-cancer pain. ${ }^{16,17)}$ It lessens symptoms associated with constipation (abdominal pain, bloating, stool consistency, and straining) and is well tolerated by patients. Lubiprostone is effective for various constipation types in patients without cancer and is recommended as a first-line drug for chronic constipation by the World Gastroenterology Organization and the Japanese Society of Gastroenterology.,18) Although lubiprostone is an effective drug for various types of constipation, there is no report on its efficacy in patients with cancer. Furthermore, the tolerance of patients with cancer to adverse events of lubiprostone, including nausea and diarrhea, remains unknown.7) The NCCN guidelines recommend lubiprostone for treating OIC that is resistant to classic agents, such as irritant laxatives and stool softeners, ${ }^{6}$ ) but this is based on studies of OIC in patients with pain not associated with cancer, and the efficacy and safety of lubiprostone to treat constipation in patients with cancer are unknown. ${ }^{19)}$ In addition, as of 2020, there are a growing number of other new laxatives available in Japan, such as linaclotide and elobixibat for the treatment of chronic 
constipation and naldemedine for the treatment of OIC, which are changing treatment options, including in combination with lubiprostone. The purpose of this study was to retrospectively investigate the efficacy and safety of lubiprostone in patients with and without cancer.

\section{PATIENTS AND METHODS}

Ethics Statement This study was approved by the Okayama University Graduate School of Medicine, Dentistry, and Pharmaceutical Sciences Ethics Committee (No. 1066). In view of the retrospective nature of the study, the need for informed consent from subjects was not required.

Study Design and Patients We retrospectively examined the efficacy and safety of lubiprostone in cancer patients compared with non-cancer patients in 250 adult ( $\geq 18$ year old) inpatients who received lubiprostone between June 2013 and May 2016. Of these, we excluded three patients who underwent laparotomy within one month prior to the start of lubiprostone, one patient with ileus, one patient with gastrointestinal bleeding, and 121 patients for whom we could not gather information from electronic medical records, leaving 124 patients as eligible (cancer, $N=67$; non-cancer, $N=57$ ). The cancer group also included patients who received anticancer drug or opioid treatment during the study period. The observation period of this study was one week before and after the start of administration of oral lubiprostone $24 \mu \mathrm{g}$ once a day or twice daily. Data on patient characteristics, including comorbidity, clinical, laboratory, and treatment data, were obtained from electronic medical records.

Efficacy Assessments The efficacy of lubiprostone was evaluated by the mean change in the frequency of BMs and defecation days at one week before and after the start of administration of oral lubiprostone. In addition, we investigated the percentage of patients with a BM within $24 \mathrm{~h}$ of first lubiprostone administration. A BM was defined as any bowel movement that occurred after lubiprostone use or after other laxative use, including $\mathrm{MgO}$ or rescue medication.

Safety Assessments We investigated the adverse events, such as diarrhea, nausea, abdominal pain, chest discomfort, and vomiting, of lubiprostone with a frequency of $5 \%$ or more in Japanese package inserts. Adverse events in the observation period were obtained from the electronic medical record. Symptoms observed before the administration of lubiprostone were excluded. Furthermore, we investigated the proportion of patients who discontinued administration of lubiprostone.

Risk Factors for Discontinuation Due to Adverse Events of Lubiprostone in All Patients and Cancer Patients We assessed the risk factors for discontinuation of lubiprostone in all patients and cancer patients. We evaluated the following risk factors of all patients: age $(\geq 65)$; sex; cancer $(+/-)$; body mass index (BMI) $(<22)$; and stimulant laxative, such as senna, use (in use/not in use). We evaluated the following risk factors of cancer patients: age $(\geq 65)$, sex, BMI $(<22)$, opioid (in use/not in use), $\mathrm{MgO}$ dosage $(\mathrm{MgO} \geq 1000 \mathrm{mg}$ ), and stimulant laxative, such as senna, use (in use/not in use).

Statistical Analyses All analyses were performed using SPSS statistical software (SPSS for Windows, version 21; SPSS Inc., Chicago, IL, U.S.A.). The $\chi^{2}$ test was used for comparisons of proportions across levels of categorical variables. For continuous variables, a $t$-test, unpaired $t$-test, or Wilcoxon rank sum test was used as appropriate. The comparison between the cancer patient group and the non-cancer patient group for time to first BM was described using Kaplan-Meier survival curves, and survival curves were compared by logrank test. The incidence of adverse events was compared between the cancer patient group and non-cancer patient group by $\chi^{2}$ test. To analyze possible associations between clinical and demographic characteristics associated with the occurrence of lubiprostone discontinuation in cancer patients, we used a two-tailed Fisher's exact test. To adjust the analysis for possible confounding factors, we used a logistic regression model that only included variables that presented an association with the occurrence of discontinuation by univariate statistical analysis with $p \leq 0.20$. Logistic regression was used to investigate multivariate associations with discontinuation.

\section{RESULTS}

Patients The patient's primary diseases are shown in Table 1. Other diagnoses included cancer of the bladder $(n=1)$, pancreas $(n=1)$, brain $(n=1)$, and germ cell $(n=1)$ in the cancer group, and sarcoidosis $(n=1)$, hepatitis $\mathrm{C}(n=1)$, arteriosclerosis obliterans $(n=1)$, amyotrophic lateral sclerosis $(n=1)$, pulmonary hypertension $(n=1)$, unidentified fever $(n=1)$, and infection $(n=1)$ in the non-cancer group. The baseline characteristics of the 124 patients included in our analysis are listed in Table 1 . There were no significant differences in sex $(p=0.102)$, age $(p=0.365)$, or laxative use $(p=1.000)$ between the patients with or without cancer. The mean serum creatinine and the percentage of patients with creatinine clearance $<30 \mathrm{~mL} / \mathrm{min}$ were significantly higher in the non-cancer group than the cancer group. The percentage of patients using $\mathrm{MgO}$ and the mean $\mathrm{MgO}$ daily dose were significantly higher in the cancer group compared with the non-cancer group. Thirty-three of the 67 cancer patients $(49.3 \%)$ were treated with cancer chemotherapy drugs: cytotoxic $(n=21)$, molecular target $(n=7)$, or combination cytotoxic and molecular target $(n=5)$. Thirty-eight of the 67 cancer patients $(56.7 \%)$ were treated with an opioid for cancer pain: oxycodone $(n=16)$, fentanyl $(n=14)$, tramadol $(n=5)$, or morphine $(n=3)$. Five of the 57 non-cancer patients $(8.8 \%)$ were administered with an opioid for postoperative pain: tramadol $(n=3)$, morphine $(n=1)$, or fentanyl $(n=1)$.

Efficacy Assessments One week before and after the start of administration of oral lubiprostone, the number of BMs and mean defecation days in the two groups were significantly increased (Figs. 1A, B). There was no significant difference in the mean change in number of BMs between the cancer and non-cancer groups $(4.52 \pm 5.71$ vs. $3.04 \pm 5.58$, mean \pm standard deviation (S.D.), respectively, $p=0.146$ ). There was no significant difference in the mean change in defecation days between the cancer and non-cancer groups (1.66 $\pm 2.18 \mathrm{vs}$. $1.00 \pm 1.76$, mean \pm S.D., $p=0.071)$. There was no significant difference in the rate of first BM within $24 \mathrm{~h}$ of the first dose of lubiprostone between the cancer and non-cancer groups (67.2 vs. 73.7\%, respectively, $p=0.641$ ) (Fig. 2).

Safety Assessments Overall, 46\% (57 of 124) of cancer and non-cancer patients had at least one lubiprostone-related adverse event during the observation period of this study. The incidence of lubiprostone-related adverse events was greater in the cancer group than in the non-cancer group (58.2 vs. $31.6 \%$, 
Table 1. Patient Characteristics $(N=124)$

\begin{tabular}{|c|c|c|c|}
\hline & Cancer $(N=67)$ & Non-cancer $(N=57)$ & $p$-Value \\
\hline Sex (female), $n(\%)$ & $33(49.3)$ & 37 (64.9) & 0.102 \\
\hline Age, mean (S.D.) & $58.4(13.6)$ & $61.3(19.8)$ & 0.365 \\
\hline BMI, mean (S.D.) & $20.9(4.2)$ & $21(4.5)$ & 0.875 \\
\hline \multicolumn{4}{|l|}{ Patient's primary disease } \\
\hline Lung cancer & 23 & & \\
\hline Hematologic malignancy & 18 & & \\
\hline Gynecologic neoplasm & 8 & & \\
\hline Head and neck cancer & 4 & & \\
\hline Sarcoma & 3 & & \\
\hline Unknown primary cancer & 3 & & \\
\hline Breast cancer & 2 & & \\
\hline Liver cancer & 2 & & \\
\hline Autoimmune disease & & 16 & \\
\hline Neuropsychiatric disorder & & 13 & \\
\hline Chronic renal failure & & 10 & \\
\hline Nephrotic syndrome & & 3 & \\
\hline Type 2 diabetes mellitus & & 2 & \\
\hline Interstitial pneumonia & & 2 & \\
\hline Parkinson disease & & 2 & \\
\hline Gonarthrosis & & 2 & \\
\hline Other & 4 & 7 & \\
\hline The number of BMs (times/week) $<3, n(\%)$ & $27(40.3)$ & $16(28.1)$ & 0.187 \\
\hline Laxative, $n(\%)$ & $64(95.5)$ & $54(94.7)$ & 1.000 \\
\hline Number of concomitant laxatives, median (range) & $3(1-6)$ & $2.5(1-5)$ & 0.437 \\
\hline $\mathrm{MgO}, n(\%)$ & $54(80.6)$ & $30(52.6)$ & $<0.001$ \\
\hline Dose of $\mathrm{MgO}(\mathrm{mg} / \mathrm{d})$, mean (S.D.) & 1097 (673) & $618(722)$ & $<0.001$ \\
\hline Stimulant laxative, $n(\%)$ & $52(77.6)$ & $52(91.2)$ & 0.051 \\
\hline Rescue medication, $n(\%)$ & $30(44.8)$ & $29(50.9)$ & 0.589 \\
\hline Initial dose of lubiprostone $(48 \mu \mathrm{g} / \mathrm{d}), n(\%)$ & $36(53.7)$ & $23(40.4)$ & 0.152 \\
\hline Maintenance dose of lubiprostone $(48 \mu \mathrm{g} / \mathrm{d}), n(\%)$ & $37(55.2)$ & $24(42.1)$ & 0.155 \\
\hline Routine use of lubiprostone, $n(\%)$ & $43(64.2)$ & $46(80.7)$ & 0.047 \\
\hline Cancer chemotherapy, $n(\%)$ & $33(49.3)$ & $0(0)$ & \\
\hline Opioid, $n(\%)$ & $38(56.7)$ & $5(8.8)$ & $<0.001$ \\
\hline Oral morphine converted amount (mg/d), mean (S.D.) & $63.2(77.5)$ & $12.3(8.7)$ & 0.154 \\
\hline $\mathrm{SCr}(\mathrm{mg} / \mathrm{dL})$, mean (S.D.) & $0.91(0.72)$ & $2.15(2.6)$ & $<0.001$ \\
\hline $\mathrm{CCr}<30(\mathrm{~mL} / \mathrm{min}), n(\%)$ & $7(10.4)$ & $20(35.1)$ & $<0.001$ \\
\hline AST (U/L), mean (S.D.) & $27.9(24.3)$ & $26.1(26.9)$ & 0.694 \\
\hline ALT (U/L), mean (S.D.) & $33.8(46.6)$ & $31.9(55.1)$ & 0.843 \\
\hline
\end{tabular}

$p$-Values were calculated by the $\chi^{2}$ test for categorical variables, and the unpaired $t$-test or Wilcoxon rank-sum test for continuous variables. ALT $=$ alanine aminotransferase, $\mathrm{AST}=$ aspartate transaminase, $\mathrm{BMI}=$ body mass index, $\mathrm{BMs}=$ bowel movements, $\mathrm{CCr}=$ creatinine clearance, $\mathrm{MgO}=\operatorname{magnesium}$ oxide, $\mathrm{SCr}=$ serum creatinine, $\mathrm{S} . \mathrm{D} .=\mathrm{stan}-$ dard deviation.

respectively, $p=0.04$ ) (Table 2). Diarrhea and nausea were the most frequently observed adverse events in this study. Other adverse events included stomach discomfort $(n=2)$, anorexia $(n=1)$, stomachache $(n=1)$, and skin rash $(n=1)$ in the cancer group, and headache $(n=2)$, stomach discomfort $(n=1)$, and hepatic disorder $(n=1)$ in the non-cancer group. The rate of discontinuation due to adverse events of lubiprostone was significantly higher in the cancer group than in the non-cancer group (28.4 vs. $10.5 \%$, respectively, $p=0.023$ ). The adverse events that most commonly led to treatment discontinuation in the cancer and non-cancer groups were diarrhea (19.4 vs. $5.3 \%$, respectively), nausea (7.5 vs. 5.3\%), abdominal pain (4.5 vs. $1.8 \%$ ), chest discomfort (4.5 vs. $0 \%$ ), and hepatic disorder (0 vs. $1.8 \%$ ).

Risk Factors for Discontinuation Due to Adverse Events of Lubiprostone in All Patients and Cancer Patients We assessed risk factors for discontinuation due to adverse events of lubiprostone in all patients by univariate statistical analysis with $p \leq 0.20$. We extracted BMI $(<22)$, cancer $(+/-)$, and stimulant laxative use as risk factors in all patients. We examined several modeled clinical factors including age $(\geq 65)$, sex, BMI $(<22)$, cancer $(+/-)$, and stimulant laxative use in all patients by logistic regression analysis. There were no significant differences in age $(p=0.228)$, sex $(p=0.665)$, or stimulant laxative use $(p=0.332)$. However, regression analysis showed BMI $(<22)$ [odds ratio $(\mathrm{OR})=4.347,95 \%$ confidence interval (CI) $1.164-16.241, p=0.029$ ] to be significantly associated with discontinuation due to adverse events of lubiprostone in all patients. Furthermore, it showed the non-cancer group $(\mathrm{OR}=0.275,95 \% \mathrm{CI}, 0.092-0.821, p=0.021)$ to have significantly lower discontinuity for adverse events of lubiprostone in all patients. In addition, we extracted BMI $(<22)$, opioid use, $\mathrm{MgO}$ dosage ( $\geq 1000 \mathrm{mg}$ ), and stimulant laxative use as risk factors for discontinuation due to adverse events of lubi- 
(A)

(B)
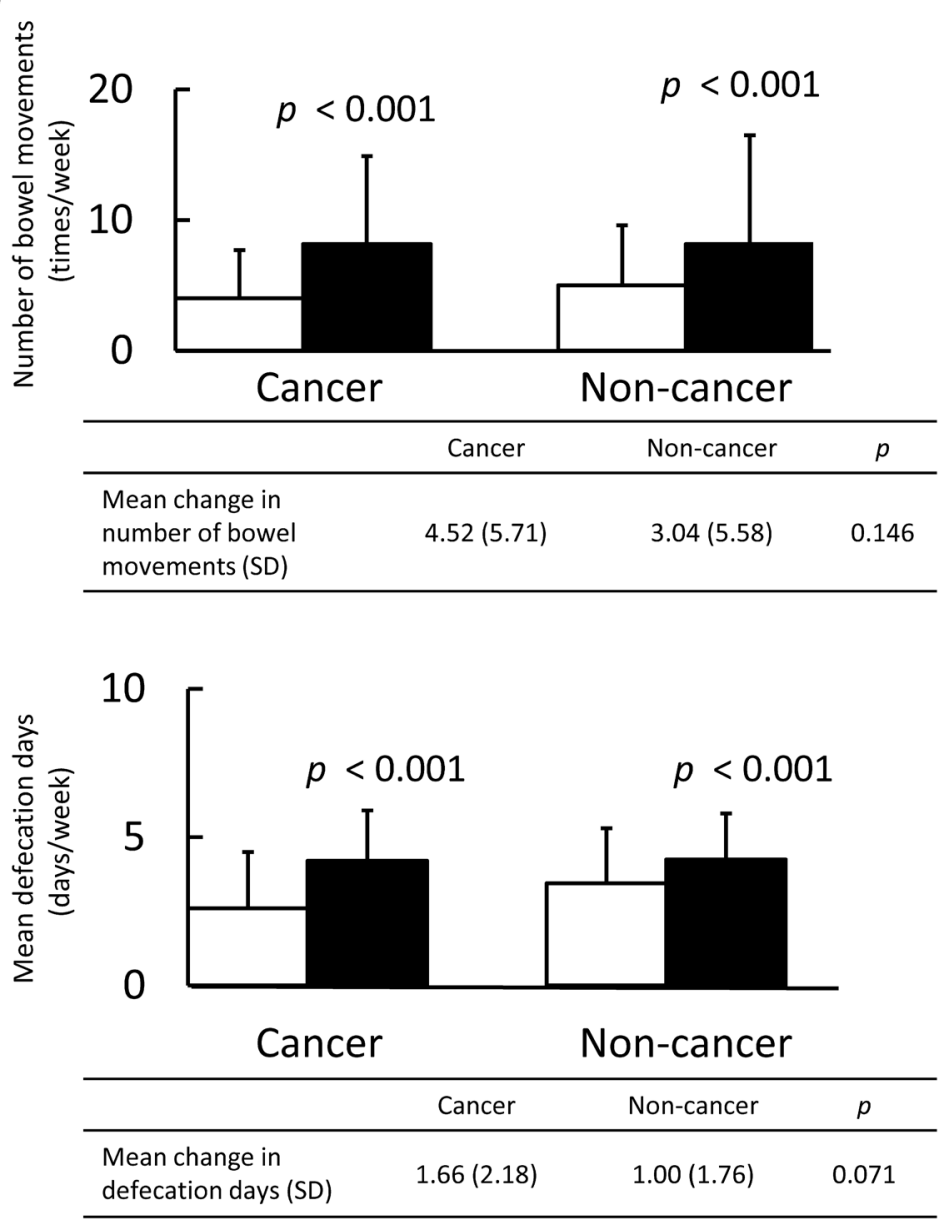

Fig. 1. Effects of Lubiprostone on the Number of Bowel Movements (A) and Defecation Days (B) Compared to One Week before and after Administration of Lubiprostone Treatment

The data are expressed as mean \pm S.D. There was no significant difference in the mean change in number of bowel movements (A) and defecation days (B) between the cancer and non-cancer groups. $\square$ : One week before the start of administration of lubiprostone; $\mathbf{\square}$ : One week after the start of administration of lubiprostone. $p$-Values were calculated by a $t$-test or unpaired $t$-test.

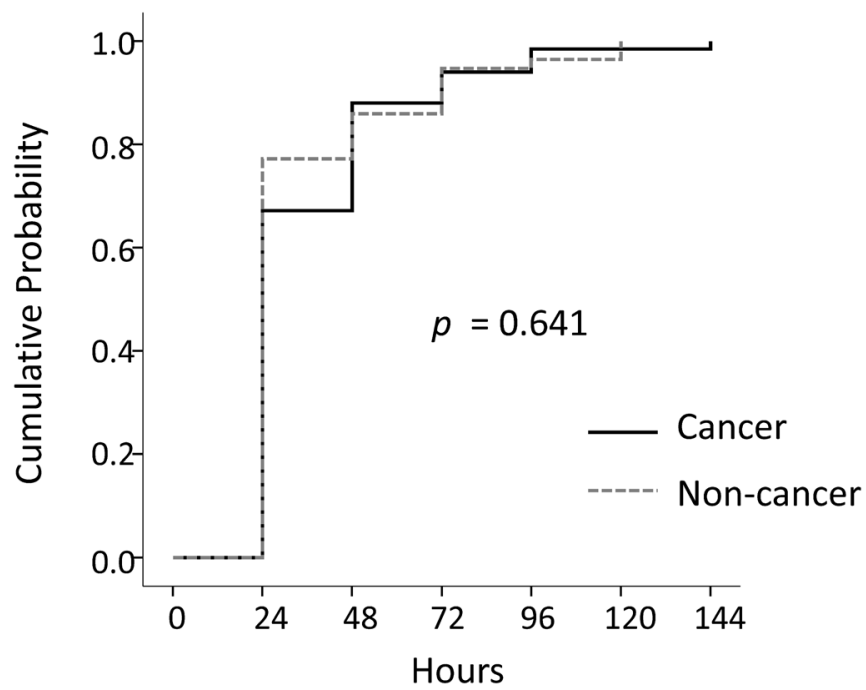

Fig. 2. Kaplan-Meier Curve for Time to First Bowel Movement

There was no significant difference in the rate of first bowel movement within $24 \mathrm{~h}$ of the first dose of lubiprostone between the cancer and non-cancer groups (67.2 vs. $73.7 \%, p=0.641)$. $p$-Values were calculated by a log-rank test. prostone in cancer patients by univariate statistical analysis. We examined several modeled clinical factors including age $(\geq 65)$, sex, BMI $(<22)$, opioid use, MgO dosage $(\geq 1000 \mathrm{mg})$, and stimulant laxative use in cancer patients by logistic regression analysis (Table 3 ). There were no significant differences in age $(p=0.747)$, sex $(p=0.757)$, or stimulant laxative use $(p=0.09)$. However, regression analysis showed BMI $(<22)$ $(\mathrm{OR}=8.655,95 \% \mathrm{CI}, 1.366-54.83, p=0.022)$ to be significantly associated with discontinuation due to adverse events of lubiprostone in cancer patients. Furthermore, it showed opioid $(\mathrm{OR}=0.134,95 \% \mathrm{CI}, 0.32-0.573, p=0.007)$, and $\mathrm{MgO}$ dosage $(\geq 1000 \mathrm{mg})(\mathrm{OR}=0.169,95 \% \mathrm{CI}, 0.36-0.783, p=0.023)$ to have significantly lower discontinuity for adverse events of lubiprostone in cancer patients.

\section{DISCUSSION}

We conducted a retrospective, single-facility observational study that compared the efficacy and safety of lubiprostone against constipation in patients with and without cancer. Lubiprostone is effective against constipation in patients with cancer. Diarrhea was a more common side effect than nausea especially in patients with cancer. The rate of lubiprostone discontinuation due to adverse effects was also higher in these 
Table 2. Adverse Events of Lubiprostone in Cancer and Non-cancer Patients

\begin{tabular}{lcc}
\hline \hline & Cancer $(N=67)$ & Non-cancer $(N=57)$ \\
\hline Lubiprostone-related AEs, $n(\%)$ & $39(58.2)$ & $18(31.6)$ \\
Diarrhea & $26(38.8)$ & $8(14.0)$ \\
Nausea & $15(22.4)$ & $5(8.8)$ \\
Vomiting & $4(6.0)$ & $1(1.8)$ \\
Abdominal pain & $3(4.5)$ & $3(5.3)$ \\
Chest discomfort & $2(3.0)$ & $3(5.3)$ \\
Other & $5(7.5)$ & $4(7.0)$ \\
Discontinuation of lubiprostone for AEs, $n(\%)$ & $19(28.4)$ & $6(10.5)$ \\
Reason for discontinuation, $n(\%)$ & $13(19.4)$ & $3(5.3)$ \\
Diarrhea & $5(7.5)$ & $3(5.3)$ \\
Nausea & $3(4.5)$ & $1(1.8)$ \\
Abdominal pain & $1(4.5)$ & 0 \\
Chest discomfort & 0 & $1(1.8)$ \\
Hepatic disorder & & \\
\hline
\end{tabular}

$p$-Values were calculated by the $\chi^{2}$ test. AE: adverse event.

Table 3. Risk Factors for Discontinuation Due to Adverse Events of Lubiprostone in Cancer Patients

\begin{tabular}{lccc}
\hline \hline Parameter & Odds ratio & $95 \%$ CI & $p$-Value \\
\hline Age $(\geq 65)$ & 1.259 & $0.312-5.084$ & 0.747 \\
Sex & 1.237 & $0.321-4.768$ & 0.757 \\
BMI $(<22)$ & 8.655 & $1.366-54.83$ & 0.022 \\
Opioid use & 0.134 & $0.32-0.573$ & 0.007 \\
Dose of MgO $(\geq 1000 \mathrm{mg})$ & 0.169 & $0.36-0.783$ & 0.023 \\
Stimulant laxative use & 0.268 & $0.58-1.226$ & 0.09 \\
\hline
\end{tabular}

$p$-Values were calculated by logistic regression. $\mathrm{BMI}=$ body mass index, $\mathrm{CI}=$ con fidence interval, $\mathrm{MgO}=$ magnesium oxide.

patients, due to the diarrhea. The risk factors for lubiprostone treatment discontinuation included low BMI, use of opioids, and $\mathrm{MgO}$ dosage.

A previous study on the efficacy of lubiprostone was based on the administration of $24 \mu \mathrm{g}$ of lubiprostone twice a day to patients with CIC. One week later, change in SBMs compared with those at the baseline was 3.66-4.61 times/week, and this effect was maintained over the 4 -week trial period. ${ }^{12,13)}$ Lubiprostone was administered at the same rate to treat OIC in patients without cancer, and the average difference between the total SBMs 12 weeks later and those at the baseline was 2.2-3.2 times/week. ${ }^{16,17)}$ The ratio of patients who achieved SBM within $24 \mathrm{~h}$ of initial lubiprostone administration $(24 \mu \mathrm{g}$, twice a day) was $61.3-75 \%{ }^{12,20)}$ for patients with CIC and IBS-C, and $38.8-50.9 \%^{16,17)}$ for OIC in patients without cancer. In the present study, average increase in BMs following lubiprostone administration in patients with cancer in a week was $4.52 \pm 5.71$ times, which was in line with the previous findings. ${ }^{12,13,16,17)}$ The initial BM was noted in approximately $70 \%$ of patients within $24 \mathrm{~h}$ of lubiprostone administration. The primary diseases of non-cancer patients in this study were mostly reported as typical underlying diseases causing chronic constipation. ${ }^{3)}$ The change in the number of BMs in patients without cancer was similar to that previously reported. ${ }^{12,13)}$ Furthermore, in the present study, because it was a retrospective study, we could not evaluate QOL; however, the number of BMs and defecation days were significantly increased by lubiprostone in both groups, and it was considered that the use of lubiprostone contributed to the improvement of daily defecation habits and QOL.

Regarding the adverse events, diarrhea (about 3-15\%), nausea (about $8-21 \%$ ), and abdominal pain (3-8\%) are common adverse events in patients with $\mathrm{CIC}$, OIC, and IBS-C. ${ }^{12-17)}$ The most common adverse event of lubiprostone usage was nausea; however, long-term administration of lubiprostone $(48 \mu \mathrm{g}$ per day for 48 weeks) to patients with CIC resulted in an increased frequency of diarrhea $(37.3 \%)$ and nausea $(27.3 \%){ }^{13)}$ In previous studies, discontinuation of lubiprostone due to adverse events occurred in $12.6-13.3 \%^{12,21)}$ of patients with CIC, 3.3-5\% ${ }^{14,15)}$ of patients with IBS-C, and 5.2-5.6\% ${ }^{17,22)}$ of patients without cancer but with OIC. In the present study, diarrhea was observed more commonly than nausea, especially in patients with cancer. The incidence of adverse events in patients without cancer was similar to these previous reports: diarrhea $(14 \%)$, nausea $(8.8 \%)$, vomiting $(1.8 \%)$, and abdominal pain $(5.3 \%)$. In patients with cancer, the incidence of adverse events was higher than previous reports: diarrhea (38.8\%), nausea $(22.4 \%)$, vomiting $(6 \%)$, and abdominal pain (4.5\%). Discontinuation of lubiprostone treatment due to adverse events occurred in $10.5 \%$ of patients without cancer, which was similar to that previously reported ${ }^{12,21)}$; however, for patients with cancer, the discontinuation rate was higher (28.4\%), and the incidence of diarrhea was especially high $(19.4 \%)$ in this study.

The efficacy of lubiprostone against constipation in patients with cancer was similar to previous reports, ${ }^{12,13,16,17,20)}$ but the incidence of adverse events, especially diarrhea, was higher, often leading to the discontinuation of treatment. However, as most adverse events were digestion-related symptoms associated with the drug's mechanism of action and not lifethreatening adverse events, it is acceptable for use in cancer patients.

In the present study, the use of opioids and anticancer drugs in the cancer patients was 56.7 and $49.3 \%$, respectively. Anticancer drugs cause constipation, ${ }^{4,7,23,24)}$ therefore, there were many patients who took classic laxatives such as $\mathrm{MgO}$ and sennosides. Some patients were administered lubiprostone when the effects of classic laxatives were insufficient. The initial dose of lubiprostone was $48 \mu \mathrm{g}$ per day for 50 and $40 \%$ of patients with and without cancer, respectively. For can- 
cer patients, routine use was significantly lower than that of non-cancer patients. This suggests that more cancer patients were using lubiprostone on an as-needed basis because of the adverse events. A combination of lubiprostone is useful for cancer patients for whom conventional laxatives are not sufficiently effective.

In the present study, the incidence of diarrhea was high in both patients with and without cancer. This may be because the patients observed in this study were already using stool softeners, such as $\mathrm{MgO}$, and irritant laxatives such as sennosides. Adding lubiprostone to these medications may have increased the incidence of diarrhea. The impact of anticancer drugs was also considered, ${ }^{23)}$ but univariate analysis did not identify the use of anticancer drugs as a risk factor for the discontinuation of lubiprostone treatment.

In the present study, we showed by multivariate analysis that the risk factors for discontinuation of lubiprostone in all patients were a BMI $<22$ and the presence or absence of cancer. Multivariate analysis identified that the risk factors for discontinuation of lubiprostone in cancer patients were a BMI $<22$, the presence or absence of opioids, and $\mathrm{MgO}$ dosage. In this study, the involvement of risk factors associated with discontinuation of lubiprostone in non-cancer patients was not shown by logistic regression analysis (not noted in the results). A BMI $<22$ was found to be a risk factor for discontinuing lubiprostone due to adverse events. Although there are some reports of an association between BMI and constipation, there appears to be no consistent evidence ${ }^{25-27)}$; however, it is unlikely that low BMI levels have a direct effect on the increase in diarrhea. Cancer patients often have cachexia with symptoms such as weight loss, malnutrition, and decreased physical function, and cachexia is associated with a BMI $<20 .{ }^{28)}$ In the present study, cancer patients with a BMI $<22$ were also considered to have precachexia. Therefore, it was possible that cancer patients with cachexia and a BMI $<22$ tolerated the drug less well and that the frequency of adverse events due to lubiprostone was increased. ${ }^{28)}$ In addition, among patients with IBS-C who were administered lubiprostone, those with a BMI $<25$ had a significantly higher incidence of nausea than those with a BMI of 25 or higher. ${ }^{29)}$ Therefore, patients with low BMI may be more likely to overdose and have adverse effects. When opioids and $\mathrm{MgO}$ of $1000 \mathrm{mg}$ or more were used, risk of discontinuation was lower. The combined use of opioids may have lessened lubiprostone-induced diarrhea as an adverse event, as opioids are known to suppress intestinal peristalsis. In Japan, ingesting more than $1000 \mathrm{mg}$ of $\mathrm{MgO}$ per day has been reported to prevent $\mathrm{OIC},{ }^{5)}$ but the optimal dose for constipation other than OIC in patients with cancer is unknown. In addition, the use of antacids, such as proton pump inhibitors and histamine blockers, is a risk factor for constipation when using $\mathrm{MgO}$ to prevent OIC. ${ }^{30)}$ Thus, it is necessary to use an increased dose $(2000 \mathrm{mg} / \mathrm{d}$ or more $)$ of $\mathrm{MgO}$ to prevent OIC when used with antacids. The weakened laxative effect of $\mathrm{MgO}$ on combined use with antacids is a drug interaction problem and thus has an impact regardless of the disease state. In the present study, $79 \%$ of patients with cancer used antacids (not noted in the result), and the average use of $\mathrm{MgO}$ was $1097 \pm 673 \mathrm{mg}$. Compared with existing reports, ${ }^{30)}$ the dose of $\mathrm{MgO}$ in this study was insufficient to prevent OIC, leading to a strong tendency to develop constipation. The Japanese package insert states that the daily dose of $\mathrm{MgO}$ for constipation is $2000 \mathrm{mg}$. In addition, hypermagnesemia due to $\mathrm{MgO}$ has been reported in elderly patients with impaired renal function, and it is recommended to start $\mathrm{MgO}$ at a low dose. ${ }^{31)}$ In this study, the daily dose of $\mathrm{MgO}$ was lower than that in the package insert, including cancer patients and non-cancer patients. The low dose of $\mathrm{MgO}$ in this study was also thought to be due to the concomitant use of lubiprostone. The combined use of lubiprostone and $\mathrm{MgO}$ was expected to have an additive effect as well as avoid side effects of $\mathrm{MgO}$. Cancer patients who received $1000 \mathrm{mg} / \mathrm{d}$ or more of $\mathrm{MgO}$ had a lower risk of discontinuation when combined with lubiprostone. On the other hand, cancer patients who received $\mathrm{MgO}$ less than $1000 \mathrm{mg} / \mathrm{d}$ had a high frequency of side effects, such as diarrhea, when used in combination with lubiprostone. Concomitant lubiprostone may be poorly tolerated in relatively mild constipation patients whose symptoms had been controlled with low doses of $\mathrm{MgO}$. On the other hand, the additive effect of lubiprostone was observed in patients taking more than a certain amount (1000 mg/d or more) of $\mathrm{MgO}$.

In the non-cancer patients, more than $30 \%$ had severe renal dysfunction and the percentage of patients with declined renal function was significantly higher among those without cancer than in those with cancer. In addition, non-cancer patients had diseases associated with renal dysfunction, such as chronic renal failure, nephrosis, diabetes, anti-neutrophil cytoplasmic antibody-associated vasculitis, and autoimmune diseases, such as dermatomyositis, in this study. Hypermagnesemia has been reported when $\mathrm{MgO}$ is administered to patients with renal disease, and even to children with normal renal function. ${ }^{32-34)}$ Therefore, lubiprostone was administered to reduce $\mathrm{MgO}$ in the non-cancer group, which has a risk of hypermagnesemia. The number of patients with concomitant $\mathrm{MgO}$ and doses were lower in the non-cancer group. Thus, lubiprostone was administered for many patients with renal disease or impaired renal function in the non-cancer group. Based on the results of this study, the number of bowel movements before and after administration of lubiprostone were similar in the cancer and non-cancer groups. Therefore, we believe that renal dysfunction does not adversely affect the efficacy of lubiprostone. The efficacy of lubiprostone in non-cancer patients was similar to that in previous reports ${ }^{12,13)}$ and we consider that the specificity of the background factors in this study did not affect the results.

In the present study, the incidence of adverse events in noncancer patients was significantly lower despite the high proportion of patients with impaired renal function. Lubiprostone may have renal function-improving effects as reported in a case report. ${ }^{35)}$ In a murine experiment, lubiprostone improved the intestinal environment, which in turn reduced the accumulation of uremic toxins in the body and suppressed the advancement of kidney damage. ${ }^{36)}$ A double-blind, randomized controlled trial involving patients with chronic renal diseases prior to dialysis is in progress in Japan to examine the decrease of uremic substances and suppression of the decline in renal functions by lubiprostone. Therefore, lubiprostone may be a safe laxative for patients with kidney damage. On the other hand, $\mathrm{MgO}$ is frequently used in Japan and is associated with a risk of hypermagnesemia with symptoms in patients with renal dysfunction, which warrants caution. ${ }^{37)}$ Continuous use of sennosides and irritant laxatives have a risk of weakened BMs and colonic melanosis. ${ }^{37)}$ Therefore, lubiprostone 
is a superior option for long-term treatment of constipation. It has been shown that the adverse events of lubiprostone are often observed in the early stage of administration, ${ }^{29)}$ therefore, understanding these adverse events at this stage may provide possibilities for adopting subsequent treatment measures. In the present study, the as-needed use of lubiprostone was high in patients with cancer, who were experiencing adverse events.

There were several limitations to the present study. First, this study was an observational study and not a randomized controlled trial. Second, a potential residual confounding effect caused by differences in factors of each group that were not examined. Third, as it was an observational study, we were unable to assess QOL scores for symptoms associated with constipation other than defecation such as abdominal pain, form and property of stool, bloating, consistency of the stool, and straining. Finally, we did not assess the efficacy and safety of lubiprostone for long-term use in cancer patients.

This was a retrospective observational study at a single facility, in which the efficacy and safety of lubiprostone use to treat constipation were compared in patients with and without cancer. We showed that lubiprostone was as effective in treating constipation in patients with cancer as without cancer. Diarrhea was the most common adverse event in patients with cancer. The rate of discontinuation of lubiprostone due to adverse events was also higher in these patients, with diarrhea being the main reason. The risk of discontinuation of lubiprostone was high in patients with a $\mathrm{BMI}<22$, and low in patients using both opioids and $\mathrm{MgO}$ at a dose of $1000 \mathrm{mg} / \mathrm{d}$ or more.

Conflict of Interest The authors declare no conflict of interest.

\section{REFERENCES}

1) Solano JP, Gomes B, Higginson IJ. A comparison of symptom prevalence in far advanced cancer, AIDS, heart disease, chronic obstructive pulmonary disease and renal disease. J. Pain Symptom Manage., 31, 58-69 (2006).

2) Vazquez Roque M, Bouras EP. Epidemiology and management of chronic constipation in elderly patients. Clin. Interv. Aging, 10, 919-930 (2015).

3) Miwa H, Torii A, Maeda K, Akiho H, Araki Y, Iijima H. Evidencebased clinical practice guidelines for chronic constipation 2017. Nankodo Press, Tokyo, pp. 1-95 (2017).

4) Larkin PJ, Sykes NP, Centeno C, Ellershaw JE, Elsner F, Eugene B, Gootjes JR, Nabal M, Noguera A, Ripamonti C, Zucco F, Zuurmond WW. The management of constipation in palliative care: clinical practice recommendations. Palliat. Med., 22, 796-807 (2008).

5) Ishihara M, Ikesue $\mathrm{H}$, Matsunaga $\mathrm{H}$, Suemaru K, Kitaichi K, Suetsugu K, Oishi R, Sendo T, Araki H, Itoh Y. A multi-institutional study analyzing effect of prophylactic medication for prevention of opioid-induced gastrointestinal dysfunction. Clin. J. Pain, 28, 373-381 (2012)

6) Swarm RA, Paice JA, Anghelescu DL, et al. Adult cancer pain, Version 3.2019, NCCN clinical practice guidelines in oncology. $J$. Natl. Compr. Canc. Netw., 17, 977-1007 (2019).

7) Thomas J. Cancer-related constipation. Curr. Oncol. Rep., 9, 278284 (2007).

8) Sykes NP. The relationship between opioid use and laxative use in terminally ill cancer patients. Palliat. Med., 12, 375-382 (1998)

9) Mancini I, Bruera E. Constipation in advanced cancer patients. Support. Care Cancer, 6, 356-364 (1998).
10) Sun X, Wang X, Wang GD, Xia Y, Liu S, Qu M, Needleman BJ, Mikami DJ, Melvin WS, Bohn LM, Ueno R, Wood JD. Lubiprostone reverses the inhibitory action of morphine on mucosal secretion in human small intestine. Dig. Dis. Sci., 56, 330-338 (2011).

11) Lacy BE, Levy LC. Lubiprostone: a chloride channel activator. $J$. Clin. Gastroenterol., 41, 345-351 (2007).

12) Barish CF, Drossman D, Johanson JF, Ueno R. Efficacy and safety of lubiprostone in patients with chronic constipation. Dig. Dis. Sci., 55, 1090-1097 (2010).

13) Fukudo S, Hongo M, Kaneko H, Takano M, Ueno R. Lubiprostone increases spontaneous bowel movement frequency and quality of life in patients with chronic idiopathic constipation. Clin. Gastroenterol. Hepatol., 13, 294-301.e5 (2015).

14) Drossman DA, Chey WD, Johanson JF, Fass R, Scott C, Panas R, Ueno R. Clinical trial: lubiprostone in patients with constipationassociated irritable bowel syndrome-results of two randomized, placebo-controlled studies. Aliment. Pharmacol. Ther., 29, 329-341 (2009).

15) Chey WD, Drossman DA, Johanson JF, Scott C, Panas RM, Ueno R. Safety and patient outcomes with lubiprostone for up to 52 weeks in patients with irritable bowel syndrome with constipation. Aliment. Pharmacol. Ther., 35, 587-599 (2012).

16) Cryer B, Katz S, Vallejo R, Popescu A, Ueno R. A randomized study of lubiprostone for opioid-induced constipation in patients with chronic noncancer pain. Pain Med., 15, 1825-1834 (2014).

17) Jamal MM, Adams AB, Jansen JP, Webster LR. A randomized, placebo-controlled trial of lubiprostone for opioid-induced constipation in chronic noncancer pain. Am. J. Gastroenterol., 110, 725-732 (2015).

18) Lindberg G, Hamid SS, Malfertheiner P, Thomsen OO, Fernandez LB, Garisch J, Thomson A, Goh KL, Tandon R, Fedail S, Wong BC, Khan AG, Krabshuis JH, LeMair A. World Gastroenterology Organisation global guideline: Constipation-a global perspective. J. Clin. Gastroenterol., 45, 483-487 (2011).

19) Hisanaga $T$, Shinjo $T$, Imai K, Katayama K, Kaneishi K, Honma H, Takagaki N, Osaka I, Matsuo N, Kohara H, Yamaguchi T, Nakajima N. Clinical Guidelines for Management of Gastrointestinal Symptoms in Cancer Patients: The Japanese Society of Palliative Medicine Recommendations. J. Palliat. Med., 22, 986-997 (2019).

20) Fukudo S, Hongo M, Kaneko H, Ueno R. Efficacy and safety of oral lubiprostone in constipated patients with or without irritable bowel syndrome: a randomized, placebo-controlled and dose-finding study. Neurogastroenterol. Motil., 23, 544-e205 (2011).

21) Lembo AJ, Johanson JF, Parkman HP, Rao SS, Miner PB Jr, Ueno R. Long-term safety and effectiveness of lubiprostone, a chloride channel (ClC-2) activator, in patients with chronic idiopathic constipation. Dig. Dis. Sci., 56, 2639-2645 (2011).

22) Spierings ELH, Rauck R, Brewer R, Marcuard S, Vallejo R. Longterm safety and efficacy of lubiprostone in opioid-induced constipation in patients with chronic noncancer pain. Pain Pract., 16, 985-993 (2016)

23) Gibson RJ, Keefe DM. Cancer chemotherapy-induced diarrhoea and constipation: mechanisms of damage and prevention strategies. Support. Care Cancer, 14, 890-900 (2006).

24) Hayashi H, Suzuki A, Ohata K, Ishihara M, Kubota Y, Kobayashi R, Shibata Y, Nakamura H, Nakamura N, Kitagawa J, Tsurumi H, Shimizu M, Itoh Y. Control of constipation in patients receiving CHOP or CHOP-like chemotherapy regimens for non-hodgkin's lymphoma. Biol. Pharm. Bull., 40, 698-702 (2017).

25) Chang JY, Locke GR, Schleck CD, Zinsmeister AR, Talley NJ. Risk factors for chronic constipation and a possible role of analgesics. Neurogastroenterol. Motil., 19, 905-911 (2007).

26) Pourhoseingholi MA, Kaboli SA, Pourhoseingholi A, MoghimiDehkordi B, Safaee A, Mansoori BK, Habibi M, Zali MR. Obesity and functional constipation; a community-based study in Iran. $J$. Gastrointestin. Liver Dis., 18, 151-155 (2009). 
27) Ballou S, Singh P, Rangan V, Iturrino J, Nee J, Lembo A. Obesity is associated with significantly increased risk for diarrhoea after controlling for demographic, dietary and medical factors: a crosssectional analysis of the 2009-2010 National Health and Nutrition Examination Survey. Aliment. Pharmacol. Ther., 50, 1019-1024 (2019)

28) Fearon K, Strasser F, Anker SD, Bosaeus I, Bruera E, Fainsinger RL, Jatoi A, Loprinzi C, MacDonald N, Mantovani G, Davis M. Muscaritoli M, Ottery F, Radbruch L, Ravasco P, Walsh D, Wilcock A, Kaasa S, Baracos VE. Definition and classification of cancer cachexia: an international consensus. Lancet Oncol., 12, 489-495 (2011)

29) Cryer B, Drossman DA, Chey WD, Webster L, Habibi S, Wang M. Analysis of nausea in clinical studies of lubiprostone for the treatment of constipation disorders. Dig. Dis. Sci., 62, 3568-3578 (2017).

30) Ibuka H, Ishihara M, Suzuki A, Kagaya H, Shimizu M, Kinosada Y, Itoh Y. Antacid attenuates the laxative action of magnesia in cancer patients receiving opioid analgesic. J. Pharm. Pharmacol., 68, 1214-1221 (2016).

31) The Japan Geriatrics Society. "Guidelines for medical treatment and its safety in the elderly 2015.”: 〈https://www.jpn-geriat-soc.or.jp/ info/topics/pdf/20170808_01.pdf), accessed 14 June, 2020.
32) Yamaguchi $H$, Shimada H, Yoshita K, Tsubata Y, Ikarashi K, Morioka T, Saito N, Sakai S, Narita I. Severe hypermagnesemia induced by magnesium oxide ingestion: a case series. CEN Case Rep., 8, 31-37 (2019)

33) Alaini A, Roldan CA, Servilla K, Colombo ES. Near death by milk of magnesia. BMJ Case Rep., 2017, bcr2016218260 (2017).

34) Tatsuki M, Miyazawa R, Tomomasa T, Ishige T, Nakazawa $T$, Arakawa H. Serum magnesium concentration in children with functional constipation treated with magnesium oxide. World J. Gastroenterol., 17, 779-783 (2011).

35) Takeshita M, Tanaka A, Nakamura T, Sato E, Node K. Effect of lubiprostone on urinary protein excretion: a report of two iga nephropathy patients with chronic constipation. Intern. Med., $\mathbf{5 8}$ 3255-3259 (2019)

36) Mishima E, Fukuda S, Shima H, Hirayama A, Akiyama Y, Takeuchi Y, Fukuda NN, Suzuki T, Suzuki C, Yuri A, Kikuchi K, Tomioka Y, Ito S, Soga T, Abe T. Alteration of the intestinal environment by lubiprostone is associated with amelioration of adenine-induced CKD. J. Am. Soc. Nephrol., 26, 1787-1794 (2015).

37) Xing JH, Soffer EE. Adverse effects of laxatives. Dis. Colon Rectum, 44, 1201-1209 (2001). 